\title{
THE EFFECTS OF PLASMODIUM FALCIPARUM AND $P$. VIVAX INFECTIONS ON PLACENTAL HISTOPATHOLOGY IN AN AREA OF LOW MALARIA TRANSMISSION
}

\author{
ROSE MCGREADY, BILLIE B. DAVISON, KASIA STEPNIEWSKA, THEIN CHO, HTEE SHEE, ALAN BROCKMAN, \\ RACHANEE UDOMSANGPETCH, SORNCHAI LOOAREESUWAN, NICHOLAS J. WHITE, STEVE R. MESHNICK, AND \\ FRANÇOIS NOSTEN \\ Shoklo Malaria Research Unit, Mae Sot, Thailand; Faculty of Tropical Medicine, and Faculty of Science, Mahidol University, \\ Bangkok, Thailand; Centre for Clinical Vaccinology and Tropical Medicine, Churchill Hospital, Oxford, United Kingdom; Division \\ of Comparative Pathology, Tulane National Primate Research Center, Covington, Louisiana; Departments of Epidemiology and \\ Microbiology and Immunology, University of North Carolina, Chapel Hill, North Carolina
}

\begin{abstract}
Placental histopathology was studied in a cohort of 204 women living in an area of low Plasmodium falciparum and $P$. vivax malaria transmission. Detection of malaria antenatally was active, by weekly peripheral blood smears, and all infections were treated. Significant histopathologic placental malaria changes (increased malaria pigment, cytotrophoblastic prominence, and presence of parasites) were found only in a minority of women who had $P$. falciparum infections in pregnancy. These changes were significantly more frequent in women with evidence of peripheral blood infection close to delivery and only in these cases were placental inflammatory cells increased. Antenatal $P$. vivax infection was associated only with the presence of malaria pigment in the placenta. All placental infections diagnosed by blood smear and 32.4\% (12 of 37) diagnosed by histopathology were associated with patent peripheral parasitemia. This study indicates that prompt treatment of peripheral parasitemias during pregnancy limits placental pathology. The effect on birth weight reduction may not result from irreversible placental changes but from the acute insult of infection. These findings emphasize the importance of treating malaria in pregnancy promptly with effective antimalarial drugs.
\end{abstract}

\section{INTRODUCTION}

The harmful effects of Plasmodium falciparum infection on the mother and baby are well recognized. ${ }^{1}$ Falciparum malaria during pregnancy reduces birth weight, and low birth weight is a major determinant of infant mortality., ${ }^{2,3}$ The majority of studies have come from areas of high stable transmission where infection is almost continuous, the mother is often asymptomatic (although more anemic), and the placenta heavily parasitized despite low parasitemias in the peripheral blood. Malaria-related reduction in birth weight predominantly affects primigravida. The dynamics of malaria in pregnancy in areas of low and unstable transmission are very different. In these areas, there is little or no background immunity, the majority of infections become symptomatic, and in falciparum malaria, severe or lethal infections may develop. Symptomatic malaria is treated, or malaria is detected actively by routine screening at antenatal clinics. This considerably limits the infections and reduces the risk of maternal death. Despite these brief self-limiting illnesses, the birth weight reductions are similar to those in high transmission settings even with a single infection episode of $P$. falciparum, and maternal anemia is a common consequence. ${ }^{4}$ Similar adverse effects have been reported in $P$. vivax infections, although the reduction in birth weight and anemia are less severe than for $P$. falciparum infections. ${ }^{5,6}$ Multigravid women are also affected: indeed in $P$. vivax infections, the reduction in birth weight is greater in multigravids. ${ }^{5}$

Several studies from Africa ${ }^{7-18}$ and one from India ${ }^{6}$, all of which were conducted in moderate to high transmission areas, have associated malaria-related histopathologic changes with poor birth indicators: predominantly low birth weight. Among these reports, only one study offered pregnant women prospective antenatal malaria screening and an open door fever clinic, ${ }^{17}$ rather than simply enrolling women at the time of delivery. This study, now more than 20 years old, included 65 women from The Gambia seen at least every six weeks (February 1979-August 1980) during pregnancy who were treated for slide-confirmed malaria with chloroquine and who had placental histology examined after delivery. For the remainder of the studies, the individual antecedent malaria episodes (rather than fever episodes) and antimalarial drug use (self-treatment, chemoprophylaxis, and treatment) while pregnant, are not detailed, although there is usually a general comment about antimalarial drug use.

There are also a few reports that describe small numbers of non-falciparum Plasmodium parasites in placental smears. ${ }^{19-22}$ There are no prospective studies of the placental histopathologic changes associated with malaria in pregnancy in areas of low transmission and no studies of the pathologic effects of $P$. vivax in pregnancy.

This paper reports on the histopathologic features of the placenta in a cohort of women followed prospectively and intensively, in an area of seasonal low malaria transmission where all four species of human malaria occur and both $P$. falciparum and $P$. vivax are prevalent. Women had weekly blood smears and all positive peripheral parasitemias were treated with appropriate antimalarials. Findings are reported for women who were treated for $P$. falciparum, $P$. vivax, or both, and compared with women who never had a positive blood smear during their pregnancy.

\section{MATERIALS AND METHODS}

Study site. Women of the Karen ethnic minority living in two camps on the northwestern border of Thailand were examined at the antenatal clinics of the Shoklo Malaria Research Unit. These camps (Shoklo and Maela) had a total population of 30,000. Médecins sans Frontières was the major health provider in the camps and a consortium of charities donated food rations. This is a hill-forested region where transmission of $P$. falciparum and $P$. vivax is low and seasonal. The maximum recorded entomologic inoculation rates were approximately 0.5 infectious bites/person/year each for these two species. Plasmodium malariae and $P$. ovale are also found, but rarely. The details of the epidemiology of malaria in this area have been previously described. ${ }^{23}$ Before the introduction of early detection and treatment at weekly ante- 
natal clinics, $P$. falciparum malaria during pregnancy was associated with maternal death. ${ }^{4}$ The prevalence of human immunodeficiency virus in pregnant women in this population is extremely low $(<0.2 \%)$.

Study design. This was an open, prospective, nonrandomized study. Within the camps, all women were encouraged to deliver with trained midwives at the Shoklo Malaria Research Unit obstetric facility. Attendance was voluntary. Although Karen women traditionally deliver at home with traditional birth attendants, the Shoklo Malaria Research Unit obstetric facility has delivered two-thirds of all babies $(>8,000)$ in the camps since 1995. A car is kept on standby for the transfer to Mae Sot District Hospital for those women who require emergency caesarean section. The purpose and the methods of this study were explained to all participants in their own language. If consent was given when the woman attended at the time of delivery (initially verbal and later written), placental specimens and cord and maternal blood were collected.

The samples were collected in two batches, one of $P$. falciparum cases and one of $P$. vivax cases. All samples collected were sent to the Tulane National Primate Research Center in Covington, Louisiana for analysis. The control specimens were taken from women with no history of malaria; however, there was a predominance of primiparae among the uninfected women.

Ethical approval. This investigation was part of a larger series of studies aimed at optimizing the drug treatment of malaria in pregnancy, which were reviewed and approved both by the ethics committee of the Faculty of Tropical Medicine, Mahidol University (Bangkok, Thailand) and the Karen Refugee Committee (Mae Sot, Thailand).

Antenatal clinics. On enrollment, a medical record that included past malaria history and treatment, and obstetric and medical problems was completed. At each weekly visit, Karen midwives assessed every woman for temperature and weight and a malaria smear was prepared for microscopy. Each woman's hematocrit was checked every two weeks. The three species of malaria identified in this study either alone or in combination were $P$. falciparum, $P$. vivax, or $P$. malariae. Malaria slide-positive women were treated with antimalarials appropriate for the species identified. Antimalarials used to treat $P$. falciparum included quinine $(10 \mathrm{mg} / \mathrm{kg}$ three times a day for seven days), mefloquine (25 mg/kg stat dose), and artesunate $(2 \mathrm{mg} / \mathrm{kg}$ once a day for seven days for uncomplicated malaria or a treatment failure, or a $4-\mathrm{mg} / \mathrm{kg}$ loading dose, followed by $2 \mathrm{mg} / \mathrm{kg}$ once a day for six days for hyperparasitemia, defined as $>4 \%$ red blood cells [RBCs] parasitized). Some women received combination therapy: clindamycin (5 mg/kg three times a day for seven days) plus quinine or artesunate, or mefloquine plus artesunate $(4 \mathrm{mg} / \mathrm{kg} /$ day for three days). Women with $P$. vivax or $P$. malariae infections were treated with chloroquine phosphate base $(10 \mathrm{mg} / \mathrm{kg}$ on days 1 and 2 and $5 \mathrm{mg} / \mathrm{kg}$ on day 3). Primaquine was not used. Antimalarials were provided by the camp dispensaries only for slide-confirmed cases. Women who attended Shoklo Malaria Research Unit antenatal clinics and had no history of malaria and no positive weekly malaria blood smears throughout their pregnancies and consented to having a blood sample at delivery fulfilled the inclusion criteria for the uninfected group.
Labor and delivery. The mother's peripheral blood was sampled and a blood smear was made at the start of the second stage of labor. The cord blood was sampled immediately after the delivery. Following clamping and cutting of the cord, the distal end of the cord was held above the level of the proximal cord and cleaned with gauze. The clamp was released and the first $5 \mathrm{~mL}$ of blood that flowed out was collected into a heparinized tube. The placental samples were collected within 10 minutes of the completion of the third stage of labor. Two 1- $\mathrm{cm}^{3}$ sections of placenta were removed from the maternal surface one-third of the distance between the cord insertion and edge of the placental disc. The placental biopsies collected before 1998 were placed in $10 \%$ buffered formalin in a $20-\mathrm{mL}$ plastic container, while those collected after 1998 were fixed in Streck tissue fixative (STF) (Streck Laboratories, Omaha, NE). Thick and thin Giemsastained blood films were made from the mother's peripheral venous blood, the infant's cord blood, and placental blood. The placental blood was collected by syringe aspiration immediately after the first incision for the biopsy specimen was made. Thick and thin blood films were examined using $1,000 \times$ magnification with an oil-immersion lens, and peripheral blood parasite density was calculated as the number of parasites present in the thick smear per 500 white blood cells or the number of infected RBCs per 1,000 RBCs. Thick films with no Plasmodium parasites observed in 200 fields were considered negative.

Newborns were weighed within one hour of birth on a Salter ${ }^{\circledR}$ scale (Salter Weight-Tronix Ltd., Manchester, United Kingdom) that was accurate to 50 grams. Placentas were weighed with the cord and membranes attached. The gestational age of all newborns was estimated by the method of Dubowitz and Dubowitz between 6 and 24 hours of life. ${ }^{24}$

Laboratory methods. Placental biopsy specimens were stored at $-25^{\circ} \mathrm{C}$ for up to 12 months in fixative $(10 \%$ buffered formalin or full strength STF) and processed and embedded in paraffin blocks by standard techniques. Three paraffin sections, each 5- $\mu \mathrm{m}$ thick, were cut and stained with either hematoxylin and eosin, Giemsa, or Prussian blue (iron stain). The hematoxylin and eosin-stained placental specimens were examined by light microscopy. The histopathologic assessments were conducted blinded to the clinical and obstetric details. Pigment deposition was assessed by examination of iron-stained sections to differentiate between hemozoin (malaria pigment [MP]) and hemosiderin, and Giemsa-stained placental sections were examined for the presence of Plasmodium-infected RBCs in the maternal and fetal blood. All placental biopsies were examined by an experienced pathologist who had no prior knowledge of the maternal characteristics, pregnancy outcome, or malaria episodes in pregnancy. The methods used were based largely on the methods reported by Bulmer and others, ${ }^{11,25}$ Benirschke and Kaufmann, ${ }^{26}$, Nelson and others, ${ }^{27}$ and Davison and others ${ }^{28,29}$ with slight modifications. The lesions that have been historically evaluated in placental malaria by other investigators ${ }^{18,30,31}$ were also evaluated in this cohort. Histologic features were scored subjectively from none/minimal to most severe on a scale of 0 to 4 (Table 1). Maternal areas included RBCs, monocytes, polymorphonuclear cells, and intervillous fibrin. Fetal areas included perivillous fibrin, basal plate fibrin, chorionic villous stroma, chorionic villous syncytiotrophoblastic layer, Hofbauer cells (feto-placental macrophages), and fetal RBCs and 
TABLE 1

Scoring system for the evaluation of placental sections for presence of malaria-associated histopathologic changes

\begin{tabular}{|c|c|c|c|c|c|}
\hline \multicolumn{6}{|c|}{ Mild $\longrightarrow$ Most severe } \\
\hline Ranking & 0 & 1 & 2 & 3 & 4 \\
\hline $\begin{array}{l}\text { Perivillous fibrin } \\
\text { deposition }\end{array}$ & Involving $<5 \%$ & Involving $5-30 \%$ & Involving $\geq 30 \%$ & - & - \\
\hline Fibrinoid necrosis & None & $\begin{array}{l}\text { One to a few } \\
\text { multifocal areas }\end{array}$ & $25-30 \%$ affected & $30-50 \%$ affected & $\begin{array}{l}\text { Greater than } 50 \% \\
\text { affected }\end{array}$ \\
\hline $\begin{array}{l}\text { Cytotrophoblast cell } \\
\text { prominence }\end{array}$ & Normal & $\begin{array}{l}\text { Few areas with } \\
\text { increased cells }\end{array}$ & $\begin{array}{l}\text { General multifocal } \\
\text { areas of increased } \\
\text { cells }\end{array}$ & $\begin{array}{l}\text { Widespread } \\
\text { increased } \\
\text { numbers of cells }\end{array}$ & $\begin{array}{l}\text { Most of the section } \\
\text { involved with } \\
\text { increased cells }\end{array}$ \\
\hline $\begin{array}{l}\text { Pigment in each } \\
\text { separate area of } \\
\text { placental section } \\
\text { as described }\end{array}$ & $\begin{array}{c}\text { No pigment } \\
\text { observed }\end{array}$ & $\begin{array}{l}\text { Very mild and hard } \\
\text { to find; small } \\
\text { amount seen in } \\
\text { entire area }\end{array}$ & $\begin{array}{l}\text { Mild but easy to } \\
\text { identify without } \\
\text { extensive exam }\end{array}$ & $\begin{array}{l}\text { Easy to identify in } \\
\text { moderate } \\
\text { amounts in } \\
\text { multiple locations }\end{array}$ & $\begin{array}{l}\text { Large amounts of } \\
\text { pigment } \\
\text { throughout the } \\
\text { area }\end{array}$ \\
\hline Syncytial knots & \multicolumn{5}{|c|}{ Counted numerically in three $40 \times$ fields with a range and then average number per field calculated } \\
\hline Mononuclear cells & \multirow{2}{*}{\multicolumn{5}{|c|}{$\begin{array}{l}\text { Counted numerically in } 10 \text { high-power fields (HPFs) }(100 \times \text { oil immersion) and expressed as an av } \\
\text { Counted numerically in } 10 \text { HPFs }(100 \times \text { oil immersion }) \text { and expressed as an average number/HPF }\end{array}$}} \\
\hline $\begin{array}{l}\text { Polymorphonuclear } \\
\text { cells }\end{array}$ & & & & & \\
\hline \multirow{2}{*}{$\begin{array}{l}\text { Parasites counted in } \\
100 \text { fields }\end{array}$} & Negative & Rare & Low & \multicolumn{2}{|c|}{ High } \\
\hline & None & 1 to a few very rare & $1-2 / \mathrm{HPF}$ & \multicolumn{2}{|c|}{ Large numbers in every HPF } \\
\hline
\end{tabular}

monocytes in fetal placental vessels (Figure 1). The amount of MP was scored subjectively and the sum of the pigment scores for all areas examined was assigned as the total MP score for each case.

The classification of Bulmer and others was also applied to the specimens. ${ }^{11}$ Briefly, placentas were classified as not infected if there was no evidence of parasites or MP, as acute infections if there was evidence of parasites and absent or minimal pigment deposition within fibrin, as chronic active infection if there were parasites and a significant amount of pigment deposition, and as chronic past infection if there was pigment but no parasites.

Definitions. Low birth weight was defined as a birth weight less than 2,500 grams. Premature infants were those with a gestational age less than 37 weeks. Intra-uterine growth retardation referred to those infants who were term $(\geq 37$ weeks gestation) and with a low birth weight. Abortion was defined as delivery before 22 completed weeks of pregnancy. Stillbirth was defined as delivery of a dead infant of greater than 22 weeks gestational age with no heartbeat or respiration. Anemia was defined as an hematocrit less than $30 \%$. A malaria episode was defined by a positive parasitemia, regardless of symptoms. A symptomatic malaria episode was defined by fever (oral temperature $>37.5^{\circ} \mathrm{C}$ ) or a history of fever in the presence of parasitemia. Massive chronic intervillositis was defined in placental specimens as a prominent inflammatory cell infiltrate in the intervillous space (IVS), composed mainly of mononuclear cells including monocytes/ macrophages and lymphocytes. ${ }^{32}$

Statistical analysis. Data were analyzed using the statistical program SPSS for Windows (SPSS Inc., Chicago, IL) and Epi-Info (Centers for Disease Control and Prevention, Atlanta, GA). The distribution of mononuclear cells/high-power field, polymorphonuclear cells/high-power field, and syncytial knots/field $(40 \times)$ were normalized by $\log$ transformation. Thus, mean values refer to the geometric mean. Normally distributed continuous data were compared between different groups of patients by the Student's $t$-test and non-normally distributed continuous data were compared by the Mann-
Whitney U test. Categorical data were analyzed by the chisquare test or Fisher's exact test. Factors possibly associated with higher MP scores were analyzed by univariate analysis.

\section{RESULTS}

Between February 1995 and February 2002, there were 213 deliveries from which samples of placental tissue were analyzed. Nine samples were excluded from the histopathologic analysis: two with very poor fixation, six with maternal hypertension, and one with bacterial intervillositis. This left 204 samples for analysis. None of the women had gestational diabetes and no infants were stillborn.

Malaria groups. The samples have been divided into four malaria groups according to the results of the prospective follow-up of the women from weekly malaria smears at the antenatal clinics: 1) women who had only P. falciparum (PF), 2 ) women who had only non- $P$. falciparum (nonPF), 3 ) women who had mixed infections of both $\mathrm{PF}$ and $P$. vivax during pregnancy either on separate occasions or at the same time (mixed), and 4) women with no positive peripheral malaria smears from weekly screening in pregnancy (uninfected). Overall, there were 175 women with 337 treated episodes of malaria and 29 women with no malaria infections documented in pregnancy. Their characteristics and birth outcomes are summarized in Table 2. The nonPF group included 30 women: two with $P$. malariae infections and 28 with $P$. vivax infections. There were no $P$. malariae infections in the mixed group. The uninfected group was significantly younger ( $P \leq 0.05$, for all comparisons) and had a greater proportion of primigravidae compared with the PF, nonPF, and mixed groups $(P=0.014, P=0.069, P=0.011)$, respectively, but this did not affect the results of the histopathologic examination of the placenta. There were no significant differences in the proportion of women in each malaria group who delivered within seven days of the last episode of malaria. There were no significant differences in the number of consultations between the groups. 


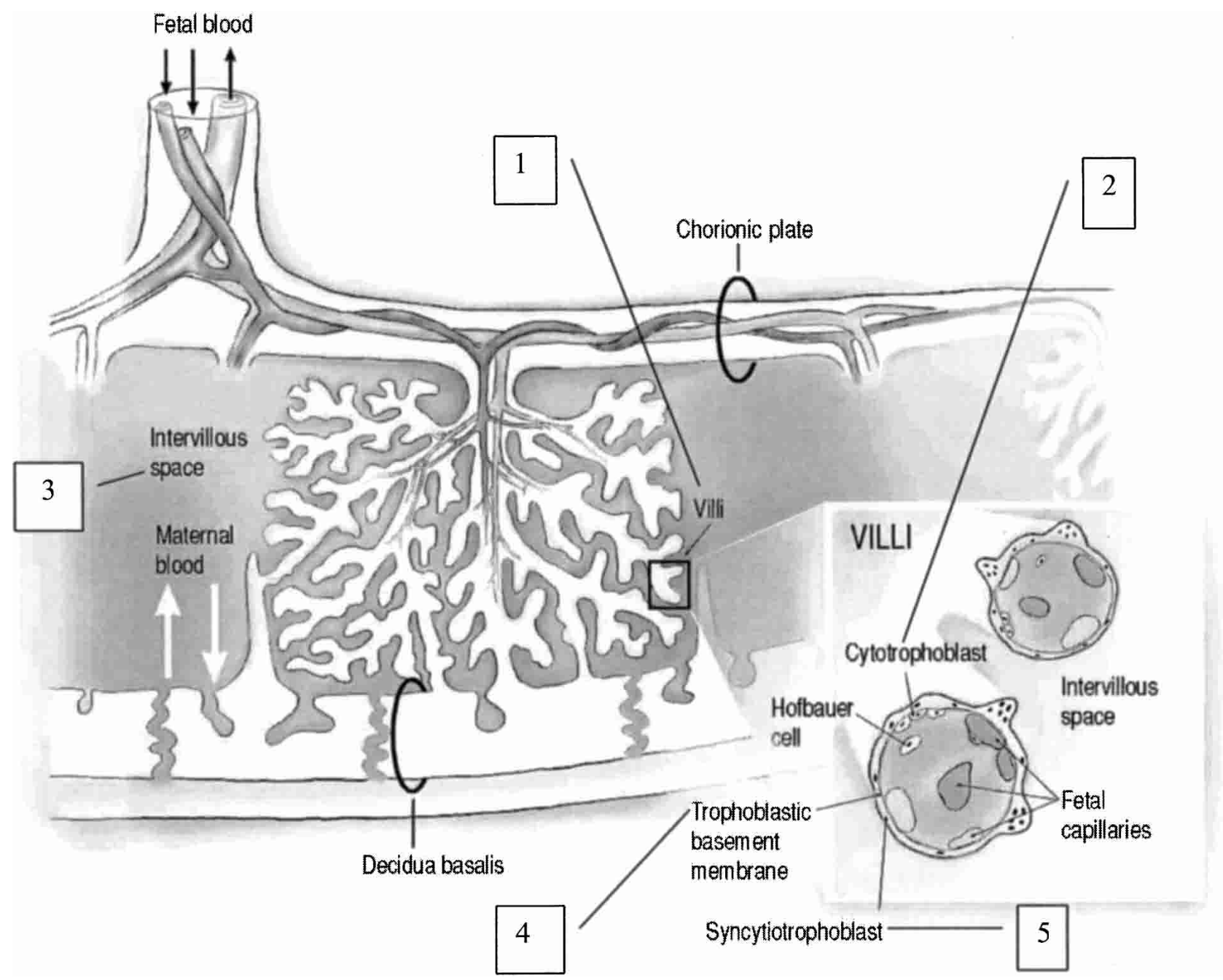

FIGURE 1. Schematic representation of the human placenta, with the inset showing a cross-section of terminal villi. $1=$ The villi are composed of fetal connective tissue and are covered by trophoblasts. The trophoblast is the parenchyma of the placenta. It is the tissue through which exchanges must occur, and it is involved in the production of placental hormones, both steroids and polypeptides. Parasites and pigments were evaluated in both maternal and fetal tissues. $\mathbf{2}=$ The cytotrophoblast (Langhan's layer) is made up of distinctly separate cells that form a continuous layer in early pregnancy. Later in pregnancy, this layer is reduced to a few scattered large pale cells with pale nuclei. Cytotrophoblastic prominence is an increase in their numbers. 3 = The severity of polymorphonuclear and mononuclear cell infiltrates is evaluated within the intervillous space (IVS). Most villi are free in the IVS and are bathed in blood from the maternal vessels. $4=$ In the area of the trophoblastic membrane placental tissue is evaluated for 1) fibrin-type fibrinoid: a blood-clotting product free of the extravillous trophoblast cells and usually in contact with the IVS and 2) matrix-type fibrinoid (embedded with trophoblast cells) and that itself is a secretory product of these cells. Fibrinoid necrosis of the villi occurs when matrix-type fibrinoid replaces villous stroma, leaving an intact trophoblastic surface. Perivillous fibrinoid is a matrix-type fibrinoid that replaces the trophoblastic cover of the villi. $\mathbf{5}=$ The outer covering of the villi is the syncytiotrophoblast, a syneytium with many dark-staining nuclei. During the latter half of pregnancy, groups of aggregated nuclei may project at the surface forming syncytial knots. (Reproduced with permission of Taylor \& Francis, London, United Kingdom, from Duffy PE, 2001. Immunity to malaria during pregnancy: different host, different parasite. Duffy PE, Fried M, eds. Malaria in Pregnancy: Deadly Parasite, Susceptible Host, 103.)

Parasites. Plasmodium-infected RBCs observed in peripheral, cord, and placental blood smears. There were $3(1.5 \%)$, $22(10.8 \%)$, and $19(9.3 \%)$, mother, cord, and placental blood smears, respectively, that were unavailable (poor quality, broken, or lost smears) for analysis. Parasitemia at the time of delivery was found in $19(9.5 \%)$ peripheral, $12(6.5 \%)$ placental and $2(1.1 \%)$ cord blood smears. All 12 women with positive placental blood parasitemia and the two women with positive cord blood parasitemia had concurrent positive peripheral blood parasitemia. All placenta (and cord) blood smear-positive cases were associated with recent parasitemic malaria, occurring a median of 1 (range $=0-3$ ) day before delivery. In women who had malaria at any time during their pregnancy, the placental blood smear parasite positivity rate was $6.9 \%$ (12 of $173,95 \%$ confidence interval [CI] $=$ $3.6-11.8 \%$ ). None of the uninfected or P. malariae-infected women had malaria parasites detected in cord, placental, or peripheral blood smears at delivery.

Parasites in placental histopathology sections. Parasites were not found in the 29 women in the uninfected group or in the $P$. malariae-infected women by histopathologic examination (Table 3 ). In women who had malaria anytime in pregnancy, the placental histopathologic parasite positivity rate was $21.3 \%$ ( 37 of $174,95 \% \mathrm{CI}=15.8-27.9 \%$ ). When parasites were detected in the maternal blood within the IVS of the placenta by histopathology, they were predominantly re- 
TABLE 2

Characteristics of Karen women attending antenatal weekly screening according to malaria groups in Northwestern Thailand*

\begin{tabular}{|c|c|c|c|c|}
\hline & $(\mathrm{PF}=90)$ & $\begin{array}{c}\text { NonPF } \\
(\mathrm{n}=30)\end{array}$ & $\begin{array}{c}\text { Mixed } \\
(\mathrm{n}=55)\end{array}$ & $\begin{array}{l}\text { Uninfected } \\
(\mathrm{n}=29)\end{array}$ \\
\hline \multicolumn{5}{|l|}{ Mother demographic and malaria episode characteristics } \\
\hline Age, years & $25(6)[16-41]$ & $26(7)[17-40]$ & $27(7)[15-45]$ & $22(6)[16-35]$ \\
\hline Gravidity, median & $2[1-10]$ & $2[1-8]$ & $3[1-10]$ & $1[1-6]$ \\
\hline Proportion primigravidae $\{n\}$ & $31.1\{28\}$ & $33.3[10]$ & $29.1\{16\}$ & $58.6\{17\}$ \\
\hline Gestational age (weeks) at first consultation, median & $14.8[3.7-39.8]$ & $13.6(6.2-34.5]$ & $14.1[1.7-34.5]$ & $13.6[3.8-39.3]$ \\
\hline Number weekly consults, median & $19[1-33]$ & $21[4-33]$ & $21[3-36]$ & $22[1-34]$ \\
\hline $\begin{array}{l}\text { Number of malaria infections detected and treated } \\
\text { antenatally, median }\end{array}$ & $1[1-4]$ & $\begin{array}{l}\text { PV } 2[1-4] \\
\text { PM } 1[1]\end{array}$ & $\begin{array}{l}\text { Total } 3[1-7] \dagger \\
\text { PF } 1[1-3] \\
\text { PV } 1[1-6] \\
\text { Mixed } 1[1]\end{array}$ & 0 \\
\hline Proportion with at least 1 symptomatic malaria episode & $63.3\{57 / 90\}$ & $53.6[15 / 28]$ & $70.9\{39 / 55\}$ & \\
\hline Proportion with malaria episode in last 7 days of pregnancy & $20.0\{18 / 90\}$ & $20.0\{6 / 30\}$ & $34.5\{19 / 55\}$ & NA \\
\hline Median no. of days from delivery to last malaria infection & $101[0-252]$ & $37[0-146]$ & $29[0-175]$ & NA \\
\hline Estimated gestational (weeks) age at first malaria episode & $20(10)[4-41]$ & $27(10)[3-40]$ & $19(9)[5-40]$ & NA \\
\hline Mean hematocrit at delivery & $31.5(4.8)$ & $36.5(3.2)$ & $31.9(3.8)$ & $34.3(3.6)$ \\
\hline Proportion of women anemic at delivery & $27.3(24 / 88)$ & 0 & $27.8(15 / 54)$ & $13.8(4 / 29)$ \\
\hline \multicolumn{5}{|l|}{ Birth outcomes } \\
\hline Viable single births & 89 (1 abortion) & 29 (excluding twins) & 55 & 29 \\
\hline Birth weight, grams & $\begin{array}{l}2,842(530) \\
{[600-3,900]}\end{array}$ & $\begin{array}{l}2,912(314) \\
{[2,400-3,750]}\end{array}$ & $\begin{array}{l}2,875(414) \\
{[2,000-3,850]}\end{array}$ & $\begin{array}{l}2,922(340) \\
{[2,300-3,650]}\end{array}$ \\
\hline Gestational age, weeks & $\begin{array}{l}39.0(2.5) \\
{[24.0-41.8]}\end{array}$ & $\begin{array}{l}39.9(1.3) \\
{[36.1-41.5]}\end{array}$ & $\begin{array}{l}39.3(1.2) \\
{[36.2-41.7]}\end{array}$ & $\begin{array}{l}39.4(1.1) \\
{[36.2-40.9]}\end{array}$ \\
\hline Proportion of low birth weight $\{\mathrm{n}\}$ & $16.9\{15\}$ & $3.4\{1\}$ & $12.7\{7\}$ & $10.3\{3\}$ \\
\hline Proportion of premature infants $\{n\}$ & $11.2\{10\}$ & $3.4\{1\}$ & $5.5\{3\}$ & $3.4\{1\}$ \\
\hline Proportion of IUGR $\{n\}$ & $10.1\{8\}$ & $3.6\{1\}$ & $9.6\{5\}$ & $10.7\{3\}$ \\
\hline \multirow[t]{2}{*}{ Placental weight, grams } & $487(94)$ & $517(105)$ & $510(104)$ & $488(62)$ \\
\hline & {$[100-700]$} & {$[350-800]$} & [300-800] & {$[300-600]$} \\
\hline \multirow{2}{*}{ Fetal/placenta weight ratio $\{\mathrm{n}\}$} & $5.7\{21\}$ & $5.9\{9\}$ & $5.7\{14\}$ & $6.1\{16\}$ \\
\hline & $6.1\{57\}$ & $5.8\{17\}$ & $5.8\{38\}$ & $6.0\{12\}$ \\
\hline
\end{tabular}

ported as rare (64.9\% [24 of 37]) and only $P$. falciparum infection accounted for high placental parasite densities, reported in $16.2 \%$ ( 6 of 37 ) of cases. Even in those with highdensity parasites there was no evidence of cytoadherence or apparent binding between infected RBCs and the syncytiotrophoblast cell layer that surrounds the placental villi. Although described by many groups as an in vitro or in vivo phenomenon, ${ }^{33,34}$ we were unable to find any unequivocal reports of in vivo cytoadherence of $P$. falciparum-infected RBCs in the placenta of malaria-infected women. The interval from the last malaria infection (positive peripheral blood smear) until delivery for women whose placentas were parasite positive by histopathology was a median of 5 (range = 0-129) days. Since $21(56.8 \%)$ of these women were positive

TABLE 3

Malaria-related placental histopathologic changes according to malaria group*

\begin{tabular}{|c|c|c|c|c|}
\hline & $\begin{array}{c}\mathrm{PF} \\
(\mathrm{n} \stackrel{=}{=} 90)\end{array}$ & $\begin{array}{l}\mathrm{PV} \text { only }{ }^{\dagger} \\
(\mathrm{n}=28)\end{array}$ & $\begin{array}{c}\text { Mixed } \\
(\mathrm{n}=55)\end{array}$ & $\begin{array}{c}\text { Uninfected } \\
(\mathrm{n}=29)\end{array}$ \\
\hline $\begin{array}{l}\text { Mononuclear cells/high-power field, } \\
\text { Geometric mean (range) }\end{array}$ & $\begin{array}{c}3.5 \ddagger \\
(1.5-95.5)\end{array}$ & $\begin{array}{c}2.7 \\
(1.5-4.8)\end{array}$ & $\begin{array}{c}3.1 \\
(1.2-9.1)\end{array}$ & $\begin{array}{c}3.2 \\
(1.5-8.7)\end{array}$ \\
\hline $\begin{array}{l}\text { Polymorphonuclear cells/high-power field, } \\
\text { Geometric mean (range) }\end{array}$ & $\begin{array}{c}3.4 \ddagger \\
(1.3-14.5)\end{array}$ & $\begin{array}{c}2.6 \\
(1.2-3.9)\end{array}$ & $\begin{array}{c}3.4 \ddagger \\
(1.7-7.8)\end{array}$ & $\begin{array}{c}3.5 \\
(1.8-8.3)\end{array}$ \\
\hline $\begin{array}{l}\text { Syncytial knots, } \\
\text { Geometric mean (range)* }\end{array}$ & $\begin{array}{c}14 \ddagger \\
(4-45)\end{array}$ & $\begin{array}{c}11 \\
(4-30)\end{array}$ & $\begin{array}{c}13 \\
(4-37)\end{array}$ & $\begin{array}{c}11 \\
(3-31)\end{array}$ \\
\hline Perivillous fibrin involving $>30 \%, \%$ & $\begin{array}{l}31.1 \neq \\
(28 / 90)\end{array}$ & $\begin{array}{c}3.6 \\
(1 / 28)\end{array}$ & $\begin{array}{c}23.6 \ddagger \\
(13 / 55)\end{array}$ & $\begin{array}{l}13.8 \\
(4 / 29)\end{array}$ \\
\hline Fibrinoid necrosis affecting $>50 \%, \%$ & $\begin{array}{c}12.2 \\
(11 / 90)\end{array}$ & $\begin{array}{c}0 \\
(0 / 28)\end{array}$ & $\begin{array}{c}9.1 \\
(5 / 55)\end{array}$ & $\begin{array}{c}6.9 \\
(2 / 29)\end{array}$ \\
\hline $\begin{array}{l}\text { Cytotrophoblastic cell prominence } \\
\text { (most of the villi involved), \% }\end{array}$ & $\begin{array}{l}18.9 \ddagger \S \\
(17 / 90)\end{array}$ & $\begin{array}{c}0 \\
(0 / 28)\end{array}$ & $\begin{array}{l}12.7 \S \\
(7 / 55)\end{array}$ & $\begin{array}{c}0 \\
(0 / 29)\end{array}$ \\
\hline Total MP score, median (range) & $2[0-18] \ddagger \S$ & $0[0-4] \S$ & $3[0-13] \ddagger \S$ & $0[0]$ \\
\hline Parasites positive by histopathology, \% & $\begin{array}{l}24.7 \ddagger \S \\
(22 / 89)\end{array}$ & $\begin{array}{c}3.6 \\
(1 / 28)\end{array}$ & $\begin{array}{l}25.5 \ddagger \S \\
(14 / 55)\end{array}$ & $\begin{array}{c}0 \\
(0 / 29)\end{array}$ \\
\hline
\end{tabular}

$* \mathrm{PF}=$ Plasmodium falciparum, $\mathrm{PV}=P$. vivax $; \mathrm{MP}=$ malaria pigment. There were no significant differences for all comparisons of $\mathrm{PF}$ versus mixed groups.

$\dagger$ Excludes P. malariae $(\mathrm{n}=2)$

$\ddagger$ Significantly higher than the PV group $(P<0.05)$.

$\S$ Significantly higher than the uninfected group $(P<0.05)$. 
in the last seven days of pregnancy, this finding of placental parasites was not unexpected. For the remaining 16 women, $7(18.9 \%)$ had their last episode detected from 11 to 30 days from delivery and 9 (24.3\%) from 31 and 129 days from delivery. The sample size was too small to compare the effects of different drug treatments for these women.

Histopathologic examination identified a greater proportion of cases with parasites in the placenta $(n=37)$ than did the placental blood smear $(n=12)$. The relationships between histopathology and blood smear results (peripheral, placenta, and cord) at the time of delivery are summarized in Table 4 for women for whom data are available. In 5 cases (1 P. falciparum and $4 P$. vivax) women were positive by placenta blood smear and negative by histopathologic examination, and in 24 cases women were negative by placental blood smear and positive by histopathologic examination (Table 4). Histopathology was more likely to agree with the placental blood smear result when the last infection before delivery was $P$. falciparum, rather than $P$. vivax. The plasmodium species were not differentiated by the histopathologic examination.

Estimated population placental and histopathologic parasite-positive rate. During the course of this study, there were 1,663 women with documented malaria ( $P$. falciparum and $P$. vivax) and 8,310 women who delivered, having attending the weekly Shoklo Malaria Research Unit antenatal clinics. Using the assumption that the women who attended the antenatal clinics who never had malaria detected would also have negative placental smears (since all in the uninfected group were negative in this study), the population parasite (all species) placental malaria smear positivity rate was estimated as $0.069 \%(95 \% \mathrm{CI}=0.04-0.12) \times 1,663 / 8,310=$ $1.4 \%(95 \% \mathrm{CI}=0.72-2.36)$. The histopathologic examination placental parasite positivity rate was significantly higher at $0.213 \%(95 \% \mathrm{CI}=0.158-0.279) \times 1,663 / 8,310=4.3 \%$ (95\% CI $=3.2-5.6)$.

Congenital malaria. There were three cases ( 2 definite and 1 probable) of congenital malaria detected by infant peripheral blood smear: two $P$. falciparum (day 0 of life, parasitemia $=36,000 / \mu \mathrm{L}$ and $216 / \mu \mathrm{L}$ ) and one $P$. vivax (day 14 of life therefore probable, parasitemia $=540 / \mu \mathrm{L})$. The mothers were on their second (quinine), fourth (mefloquine), and first (chloroquine) days of treatment. The $P$. vivax case had negative peripheral blood smears on days 0 and 7 of life. All three cases had placental blood smear parasitemias. Only the $P$. vivax case also had a positive cord blood parasitemia. Both babies with $P$. falciparum were symptomatic for malaria and one died of severe malaria on day 6 of life. The infant who survived was the only one to have parasites by histopathology. In this case, there were more infected RBCs than uninfected RBCs in the IVS and no parasites were observed within fetal blood vessels. The pigment was not in fibrin, only in maternal RBCs and white blood cells, indicating an acute case of severe malaria.

Malaria pigment. Of the 204 placental samples 52\% (106 of 204) were contaminated by formalin pigment (including samples of the uninfected group) due to improper fixation and these could not be used to reliably assess MP. When the 98 women with reliable MP were compared with the 106 women with unreliable MP, no significant differences in their baseline characteristics were found.

Malaria pigment was observed in several discrete locations; maternal erythrocytes in association with intraerythrocytic parasites, maternal white blood cells (both monocytes and polymorphs) following phagocytosis, and both maternal and fetal peri-villous fibrin and the basal plate fibrin (these were most frequently observed), and to a lesser extent in the chorionic villous stroma and chorionic villous syncytiotrophoblastic layer and fetal Hofbauer cells (Figure 2). There was no MP deposition in the uninfected group. There was also no MP deposition in either of the placentas of the two P. malariae cases and they have not been included for further analysis of MP.

The species of malaria affected the locations where MP could be identified (Figure 2). While the PF and mixed groups tended to have the same distribution of MP, in the $P$. vivaxinfected group the MP deposits were found less widely distributed and in lower amounts, except for in maternal monocytes.

Women in the PF and mixed groups had higher amounts of MP than those in the $P$. vivax-infected group (Figure 2). The total MP score was significantly higher in the $P$. vivax-infected group compared with the uninfected group $(P=0.004)$ (Table 3$)$ and was increased significantly $(P<0.05) 1)$ in women with high maternal $P$. falciparum parasitemia, 2) in primigravidae, 3 ) in symptomatic cases, 4) when malaria occurred during the seven days before delivery (Figure 3), and 5 ) in women with high mononuclear cell counts in the IVS.

TABLE 4

Relationship of blood smear results per site and placental histopathologic results from specimens collected at delivery*

\begin{tabular}{|c|c|c|c|c|}
\hline \multirow{3}{*}{$\begin{array}{l}\text { Site of delivery } \\
\text { blood smear }\end{array}$} & \multirow{3}{*}{$\begin{array}{c}\text { Placental } \\
\text { histopathologic } \\
\text { result }\end{array}$} & \multicolumn{3}{|c|}{ Blood smear result } \\
\hline & & \multirow[b]{2}{*}{ Negative \% (n) } & \multicolumn{2}{|l|}{ Positive } \\
\hline & & & Plasmodium falciparum positive $\%(\mathrm{n})$ & P. vivax positive $\%(\mathrm{n})$ \\
\hline \multirow{2}{*}{ Mother Peripheral } & + & $14(25 / 179)$ & $91.7(11 / 12)$ & $14.3(1 / 7)$ \\
\hline & - & $86(156 / 179)$ & $8.3(1 / 12)$ & $85.7(6 / 7)$ \\
\hline \multirow[t]{4}{*}{ Placenta } & + & $14(24 / 170)$ & $87.5(7 / 8)$ & 0 \\
\hline & & $\mathrm{PF}=12, \mathrm{PV}=1$, mixed $=11 \#$ & $\mathrm{PF}=5$, mixed $=2 \dagger$ & - \\
\hline & - & $86(146 / 170)$ & $12.5(1 / 8)$ & $100(4 / 4)$ \\
\hline & & $\mathrm{PF}=60, \mathrm{PV}=24$, mixed $=38$, uninfected $=24$ & $\mathrm{PF}=1$ & $\mathrm{PV}=3$, mixed $=1 \ddagger$ \\
\hline \multirow[t]{2}{*}{ Cord } & + & $17(30 / 177)$ & $100(1 / 1)$ & 0 \\
\hline & - & $83(157 / 177)$ & 0 & $100(1 / 1)$ \\
\hline
\end{tabular}

$* \mathrm{n}=$ women with both smear and histopathology results available for comparison; $\mathrm{PF}=P$. falciparum; $\mathrm{PV}=P$. vivax. For women in the mixed group, the last recorded infections in pregnanc were $\mathrm{PF}$ in two cases, $\mathrm{PV}$ in seven cases, and mixed in two cases.

$\dagger$ PF for both cases.

$\doteqdot \mathrm{PV}$ for one case.

\# PF in 2 cases, Rv in 7 cases and mixed in 2 cases. 


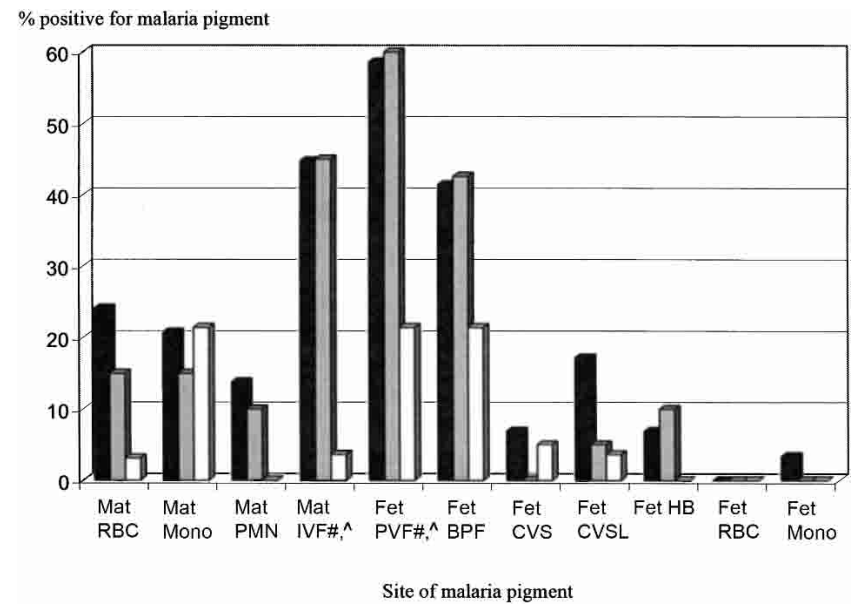

FIGURE 2. Proportion of placentas with malaria pigment in relation to the type of Plasmodium infection during pregnancy. Black bars $=P$. falciparum; gray bars $=$ mixed infections; white bars $=$ $P$. vivax . Mat $=$ maternal; Fet $=$ fetal $\mathrm{HB}=$ Hofbauer cells (fetoplacental macrophages); RBCs $=$ red blood cells; $\mathrm{PMN}=$ polymorphonuclear cells; PVF = perivillous fibrin; $\mathrm{CVS}=$ chorionic villous stroma; Mono $=$ monocytes. $\mathrm{IVF}=$ intervillous fibzin; $\mathrm{BPF}=$ basal plate fibzin; CVSL = chorionic villous syncytiotrophoblastic layer. Only statistically significant $(P<0.05)$ differences are shown. \#P. falciparum group significantly higher than the $P$. vivax group. ${ }^{\wedge}$ Mixed infection group significantly higher than the $\mathrm{P}$. vivax group.

For women infected with $P$. vivax, no identifiable factors were significantly associated with increased total MP scores probably because of the small numbers.

Other histopathologic effects on the placenta. Apart from the presence of parasites and the total pigment score (detailed earlier), the only other significant malaria placental change compared with the control group was greater cytotrophoblastic prominence in the PF and mixed groups (Table 3).

Effects of gravidity and time of infection on placental changes. Since there were no significant differences between the histopathology of the PF and mixed groups (Table 3),

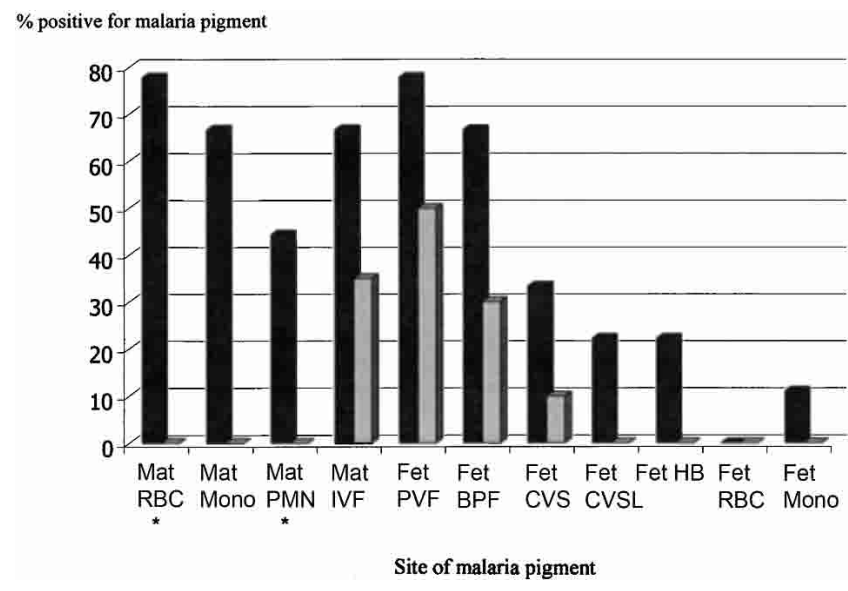

FiguRE 3. Proportion of placentas with malaria pigment in relation to the timing of Plasmodium falciparum infection. Black bars $=$ $P$. falciparum $\leq 7$ days before delivery; grey bars $=P$. falciparum $>7$ days before delivery. For definitions of abbreviations, see Figure 2. Only statistically significant $(P<0.05)$ differences are shown. $* P$. falciparum $\leq 7$ days before delivery group significantly higher than the $P$. falciparum $>7$ days before delivery group. these groups were pooled for the analysis of the effects of gravidity and time of infection on placental histopathology.

Primigravida scored significantly higher than multigravida for the following parameters: total median MP score $=5$ (range $=0-18)$ versus 1.0 (range $=0-13) ; \mathrm{P} \leq 0.001$; presence of parasites by histopathology $=41.9 \%$ (18 of 43 ) versus $17.8 \%$ (18 of 101); $P=0.003$; and geometric mean number of mononuclear cells $=4.1$ (range $=1.7-95.5)$ versus 3.1 (range $=1.2-20.0) ; P=0.017$. Polymorphonuclear cells, syncytial knots, perivillous fibrin, fibrinoid necrosis, and cytotrophoblastic prominence did not differ significantly between primigravida and multigravida.

The pooled PF and mixed groups was subdivided according to the time of the last malaria episode in pregnancy: malaria in the previous seven days and malaria before the last seven days of pregnancy. The geometric mean mononuclear cell count in the IVS was significantly higher in the former group: $5.0($ range $=1.5-95.5)$ compared with $3.1($ range $=1.2-20.0)$ in the latter group $(P<0.001)$. The median MP score was also significantly higher in the group with more recent infections (6 [range $=0-18$ ] versus 2.0 [range $=0-9$ ]; $P=0.006)$. No significant differences were observed when other aspects of placental histopathology were compared using this subdivision.

Bulmer classification. When the histopathologist applied the Bulmer classification to 98 placental samples where pigment could be assessed confidently, all specimens in the uninfected group $(\mathrm{n}=19)$ were classified as Bulmer negative (absence of parasites and pigment). A large proportion of the placentas from women with confirmed malaria were also classified as Bulmer negative: $\mathrm{PF}=34.5 \%$ (10 of 29$)$, nonPF $=$ $66.7 \%$ (20 of 30 ), and mixed $=30.0 \%$ (6 of 20 ). Overall, nearly half of the women who had malaria during pregnancy $(\mathrm{n}=79)$ were classified as Bulmer negative: $45.6 \%$ (36 of 79). If this comparison was confined to women who had at least one $P$. falciparum infection in pregnancy, then $27.1 \%$ (16 of 59 ) of the cases would have been misclassified using this system.

Massive chronic intervillousitis (MCI). There were three (1.7\%, 3 of 175$)$ women who had classic MCI in association with malaria in pregnancy (see Materials and Methods). All cases were in primigravida with acute symptomatic $P$. falciparum malaria that was being treated at the time of delivery. None had a documented episode of $P$. vivax malaria at any time during pregnancy. Deliveries occurred on days $2(n=2)$ and $4(n=1)$ of treatment. All three babies were of low birth weight and two were also premature, both of whom died. All three women who had MCI had parasites detected by histopathology and one of these was also positive by placental smear.

\section{DISCUSSION}

This is the first investigation of the placenta histopathology in $P$. falciparum and $P$. vivax malaria-infected pregnant women in an area of low transmission. It also differs from previous studies because all women were screened for malaria each week by peripheral blood smears and all women with malaria positive smears were treated promptly regardless of symptoms. Thus, there was an accurate history of malaria infections preceding delivery. It differs from the study by Watkinson and Rushton ${ }^{17}$ in that women were screened for malaria on average 20 times, compared with 8 times in The Gambia, and because treatment of women on the borders of 
Thailand is complicated by multidrug resistance in $P$. falciparum. In this area, the first line antimalarial agent for pregnant women, supervised quinine $(10 \mathrm{mg} / \mathrm{kg}$, three times a day for seven days), has a polymerase chain reaction-confirmed failure rate of $33 \%(95 \% \mathrm{CI}=9.2-56.7){ }^{35}$

Enormous numbers of parasites and macrophages in the IVS and increased fibrinous deposits containing pigment and macrophages with focal necrosis of the adjacent syncytiotrophoblast have consistently been reported in previous studies, ${ }^{31}$ but were uncommon in the present series. The total MP score was the most significant marker of previous malaria infection, occurring in approximately $50 \%$ of women with documented malaria and never present in the uninfected women. Large numbers of placental parasites, as are reported commonly from areas of high transmission, were extremely rare in the current series. Parasites were predominantly reported as rare and high counts only occurred in women infected with $P$. falciparum, not $P$. vivax. Cytotrophoblastic prominence was also significantly higher in women with $P$. falciparum infection than in uninfected women. Increased numbers of mononuclear cells in the IVS became significantly higher than in the uninfected women only when the analysis was confined to $P$. falciparum infection in the last seven days of pregnancy. The rate of massive chronic intervillositis was also very low $(1.7 \%, 3$ of 175$)$ when compared with the largest reported series from Tanzania, $(6.3 \%, 74$ of 1,179).

Despite weekly screening and prompt antimalarial treatment, $21 \%$ of the women still had parasites observed by histopathology in their placenta at the time of delivery. The presence of parasites in the placenta in $14 \%$ of the women whose infection had been cleared from the peripheral blood (Table 4) may be indicative of drug resistance and may be the result of the modified pharmacokinetic and pharmacodynamic properties of antimalarial drugs in pregnancy. ${ }^{36-39}$ In either case, malaria parasites are able to persist in the placenta despite being cleared form the peripheral blood, at least below the level of detection by microscopy, as suggested in an earlier case report. ${ }^{40}$

The malaria-associated placental changes occurred only in women whose malaria infections were detected antenatally or at delivery, unlike the Watkinson and Rushton cohort, ${ }^{17}$ in which $69 \%$ (27 of 39) of the women had a pigmented placenta but no peripheral parasitemia recorded during pregnancy. Thus in this series, there was no evidence of cryptic malaria; all infections became patent.

These differences in placental histopathology can, in part, be accounted for by the attack rates experienced in pregnancy in high and low transmission areas. However, this does not explain why there is such a big difference in placental changes, but similar reported reductions in birth weights. ${ }^{4}$ In this cohort, placental changes were most marked when infection was recent, often while women were receiving treatment for a malaria episode. This suggests that early detection and treatment allows the placenta to recover as hypothesized by Watkinson and Rushton. ${ }^{17}$ The effect on birth weight reduction may result not from the physical presence of irreversible placental changes but from the acute insult. The immune response via mechanisms such as local or systemic release of pro-inflammatory cytokines may also play an important role in birth weight reduction. ${ }^{41-43}$

Placental changes (increased number of inflammatory cells, fibrin deposition, cytotrophoblastic prominence, and syncytial knotting) were significantly greater in women infected with $P$. falciparum compared with women infected with $P$. vivax. This again implies that persistent pathologic damage to the placenta is not the most determinant factor in birth weight reduction since infants of women infected with $P$. vivax during pregnancy also show significant birth weight reduction. ${ }^{5}$ This is similar to a report by Jelliffe on 23 cases of infection with $P$. malariae during pregnancy in Uganda. ${ }^{22}$ Infections with both species ( $P$. falciparum and $P$. vivax) during the antenatal period did not result in placental changes different from those of infection with $P$. falciparum alone. Placental changes (increased inflammatory cells, fibrin deposition, cytotrophoblastic prominence and syncytial knotting) were significantly greater in women infected with $P$. falciparum compared with women infected with $P$. vivax, which again implies that persistent pathologic damage to the placenta is not the most determinant factor in birth weight reduction.

This study shows that malaria in pregnancy commonly recovers without leaving a residue of parasites and pigment in placental tissues. Absence of parasites and pigment on placental pathology is the Bulmer definition of "not infected" placentas. ${ }^{25}$ Schulman and others cite "placental histology as the most sensitive measure currently available for the diagnosis of malaria in pregnancy". 8 Placental malaria has been used as a major end point in intervention trials in pregnancy. ${ }^{44-47}$ The data of Watkinson and Rushton in The Gambia $^{17}$ (a high transmission setting) and the data presented here contradict this as a sensitive marker of malariaassociated pathologic processes, particularly in areas of lower transmission. More than one-fourth of the women with documented $P$. falciparum infection during pregnancy would have been classified as negative using the Bulmer classification in this cohort (Bulmer score: sensitivity $=66 \%$, specificity $=$ $100 \%)$. A similar proportion of women $(24 \%, 12$ of 50$)$ in the cohort of Watkinson and Rushton ${ }^{17}$ with treated peripheral parasitemia during pregnancy also would have been classified as negative. Frequent peripheral malaria smears in pregnant Karen women proved to be a much more sensitive measure of malaria infection during pregnancy than placental histopathologic classification. Thus, malaria in the placenta at delivery should not be considered a reliable proxy for malaria during pregnancy.

In a normal pregnancy, the fetus gains an average of 300-400 grams between 36 and 38 weeks and again between 38 and 40 weeks of gestation. Anemia in the mother at delivery is a major factor in post-partum hemorrhage, one of the leading two causes of maternal death in developing countries. Two doses of intermittent sulfadoxine-pyrimethamine (SP) preventive treatment are widely recommended at the beginning of each trimester (but not at term) to reduce low birth weight and anemia. Our data suggest that dosing closer to delivery may have added benefit but alternatives to SP are needed. The findings presented here advocate more active antenatal screening and emphasize the importance of treating all episodes of parasitemia in pregnant women irrespective of symptoms with an effective antimalarial drug.

Received August 14, 2003. Accepted for publication December 15, 2003.

Acknowledgments: We thank the pregnant women who attended the Shoklo Malaria Research Unit antenatal clinics, the Karen midwives, and the laboratory staff, and expatriate doctors (Christine Luxem- 
burger, Michele van Vugt, Leopoldo Villegas, Elizabetta Leonardi, Robert Hutagalung, and Elizabeth Ashley) working at Shoklo and Maela Refugee camps for their support; Renee Grow, Carol Coyne, and Maurice Duplantis for their excellent technical support in preparation of the slides for histopathology; Associate Professor Lilly Dubowitz for training and quality control of gestational age assessment; Khun Patchari Prakongpan, Tip Rutchaitrakul, and Cherise Rohr for their friendly logistical support; and Professor Bernard Brabin for his review of the manuscript.

Financial support; This work was supported by the National Institutes of Health (NIH) Public Health Service Grant P51RR00164 to the Tulane National Primate Research Center and NIH (National Institute of Allergy and Infectious Diseases) grant 5 RO1 AI-42400. The Shoklo Malaria Research Unit is part of the Wellcome-Mahidol University-Oxford Tropical Medicine Research Program funded by the Wellcome Trust of Great Britain. Part of this work was supported by PREMA-EU (Contract no PREMA-EU- ICA4-CT-2001-10012)

Authors' addresses: Rose McGready, Thein Cho, Htee Shee, Alan Brockman, and François Nosten, Shoklo Malaria Research Unit, PO Box 46, Mae Sot, Thailand, 63110, Telephone: 66-55-531-531, Fax: 66-55-525-440, E-mail: shoklo@cscoms.com. Billie B. Davison, Division of Comparative Pathology, Tulane National Primate Research Center, 18703 Three Rivers Road, Covington, LA. 70433, Telephone: 985-871-6307, Fax: 985-871-6271, E-mail: billie@tpc.tulane.edu. Kasia Stepniewska, Sornchai Looareesuwan, and Nicholas J. White, Faculty of Tropical Medicine, Mahidol University, Bangkok, 10400, Thailand, Telephone: 66-2246-0832, Fax: 66-2246-7795, E-mail: tmwu@ diamond.mahidol.ac.th. Rachanee Udomsangpetch, Faculty of Science, Mahidol University, Bangkok, 10400 Thailand, E-mail: scrud@ mucc.mahidol.ac.th. Steve R. Meshnick, Department of Epidemiology and Microbiology and Immunology, University of North Carolina, Chapel Hill, NC 27599-7435, Telephone: 919-966-7414, Fax: 919966-2089, E-mail: meshnick@unc.edu.

\section{REFERENCES}

1. Brabin B, Maxwell S, Chimsuku L, Verhoeff F, van der Kaay HJ, Broadhead R, Kazembe P, Thomas A, 1993. A study of the consequences of malarial infection in pregnant women and their infants. Parassitologia 35: 9-11.

2. Brabin BJ, 1991. The Risks and Severity of Malaria in Pregnant Women. Geneva: World Health Organization, 1-34.

3. Menendez C, 1995. Malaria during pregnancy: a priority area of malaria research and control. Parasitol Today 11: 178-183.

4. Nosten F, ter Kuile F, Maelankirri L, Decludt B, White NJ, 1991. Malaria during pregnancy in an area of unstable endemicity. Trans $R$ Soc Trop Med Hyg 85: 424-429.

5. Nosten F, McGready R, Simpson JA, Thwai KL, Balkan S, Cho T, Hkirijaroen L, Looareesuwan S, White NJ, 1999. Effects of Plasmodium vivax malaria in pregnancy. Lancet 354: 546-549.

6. Singh N, Shukla MM, Sharma VP, 1999. Epidemiology of malaria in pregnancy in central India. Bull World Health Organ 77: $567-572$.

7. Rogerson SJ, Pollina E, Getachew A, Tadesse E, Lema VM, Molyneux ME, 2003. Placental monocyte infiltrates in response to Plasmodium falciparum malaria infection and their association with adverse pregnancy outcomes. Am J Trop Med Hyg 68: 115-119.

8. Shulman CE, Marshall T, Dorman EK, Bulmer JN, Cutts F, Peshu N, Marsh K, 2001. Malaria in pregnancy: adverse effects on haemoglobin levels and birthweight in primigravidae and multigravidae. Trop Med Int Health 6: 770-778.

9. Menendez C, Ordi J, Ismail MR, Ventura PJ, Aponte JJ, Kahigwa E, Font F, Alonso PL, 2000. The impact of placental malaria on gestational age and birth weight. J Infect Dis 181: $1740-1745$.

10. Leopardi O, Naughten W, Salvia L, Colecchia M, Matteelli A, Zucchi A, Shein A, Muchi JA, Carosi G, Ghione M, 1996. Malaric placentas. A quantitative study and clinico-pathological correlations. Pathol Res Pract 192: 892-898, discussion 899-900.

11. Bulmer JN, Rasheed FN, Morrison L, Francis N, Greenwood $\mathrm{BM}, 1993$. Placental malaria. II. A semi-quantitative investigation of the pathological features. Histopathology 22: 219-225.
12. Meuris S, Piko BB, Eerens P, Vanbellinghen AM, Dramaix M, Hennart P, 1993. Gestational malaria: assessment of its consequences on fetal growth. Am J Trop Med Hyg 48: 603-609.

13. Ibhanesebhor SE, Okolo AA, 1992. Placental malaria and pregnancy outcome. Int J Gynaecol Obstet 37: 247-252.

14. Kaushik A, Sharma VK, Sadhna, Kumar R, Mitra R, 1992. Malarial placental infection and low birth weight babies. Mater Med Pol 24: 109-110.

15. Testa J, Awodabon J, Lagarde N, Olivier T, Delmont J, 1990. Plasmodial indices and malaria placentopathy in 299 parturients in Central Africa. Med Trop (Mars) 50: 85-90.

16. Anagnos D, Lanoie LO, Palmieri JR, Ziefer A, Connor DH, 1986. Effects of placental malaria on mothers and neonates from Zaire. Z Parasitenkd 72: 57-64.

17. Watkinson M, Rushton DI, 1983. Plasmodial pigmentation of placenta and outcome of pregnancy in West African mothers. BMJ 287: 251-254.

18. Walter PR, Garin Y, Blot P, 1982. Placental pathologic changes in malaria. A histologic and ultrastructural study. Am J Pathol 109: 330-342.

19. Garnham P, 1938. The placenta in malaria with special reference to the reticulo-endothelial immunity. Trans $R$ Soc Trop Med Hyg 32: 13-48.

20. Bruce-Chwatt LJ, 1952. Malaria in African infants and children in southern Nigeria. Ann Trop Med Parasitol 46: 173-200.

21. Bachschmid I, Soro B, Coulibaly A, Philippe E, Kingston L, Kien T, Rey JL, 1991. Malaria infection during childbirth and in newborns in Becedi (Ivory Coast). Bull Soc Pathol Exot 84: 257-265.

22. Jelliffe EF, 1968. Low birth-weight and malarial infection of the placenta. Bull World Health Organ 38: 69-78.

23. Luxemburger C, Thwai KL, White NJ, Webster HK, Kyle DE, Maelankirri L, Chongsuphajaisiddhi T, Nosten F, 1996. The epidemiology of malaria in a Karen population on the western border of Thailand. Trans R Soc Trop Med Hyg 90: 105-111.

24. Dubowitz MS, Dubowitz V, 1977. Gestational Age of the Newborn: A Clinical Manual. Boston: Addison Wesley.

25. Bulmer JN, Rasheed FN, Francis N, Morrison L, Greenwood BM, 1993. Placental malaria. I. Pathological classification. Histopathology 22: 211-218.

26. Benirschke K, Kaufmann P, 1995. Pathology of the Human Placenta. New York: Springer-Verlag.

27. Nelson D, Swanson P, Davison B, Baskin G, Enders A, 1997. Ontogenic and pylogenetic evaluation of the presence of fibrin type fibrinoid in the villous hemochorial placenta. Placenta 18: 605-608.

28. Davison BB, Cogswell FB, Baskin GB, Falkenstein KP, Henson EW, Tarantal AF, Krogstad DJ, 1998. Plasmodium coatneyi in the rhesus monkey (Macaca mulatta) as a model of malaria in pregnancy. Am J Trop Med Hyg 59: 189-201.

29. Davison BB, Cogswell FB, Baskin GB, Falkenstein KP, Henson EW, Krogstad DJ, 2000. Placental changes associated with fetal outcome in the Plasmodium coatneyi/rhesus monkey model of malaria in pregnancy. Am J Trop Med Hyg 63: 158-173.

30. Ordi J, Ismail MR, Ventura PJ, Kahigwa E, Hirt R, Cardesa A, Alonso PL, Menendez C, 1998. Massive chronic intervillositis of the placenta associated with malaria infection. Am J Surg Pathol 22: 1006-1011.

31. Duffy PE, 2001. Immunity to malaria during pregnancy: different host, different parasite. Duffy PE, Fried M, eds. Malaria in Pregnancy: Deadly Parasite, Susceptible Host. London and New York: Taylor \& Francis, 71-126.

32. Nebuloni M, Pallotti F, Polizzotti G, Pellegrinelli A, Tosi D, Giordano F, 2001. Malaria placental infection with massive chronic intervillositis in a gravida 4 woman. Hum Pathol 32: 1022-1023.

33. Bray RS, Sinden RE, 1979. The sequestration of Plasmodium falciparum infected erythrocytes in the placenta. Trans $R$ Soc Trop Med Hyg 73: 716-719.

34. Andrews KT, Lanzer M, 2002. Maternal malaria: Plasmodium falciparum sequestration in the placenta. Parasitol Res 88: 715723.

35. McGready R, Brockman A, Cho T, Cho D, van Vugt M, Luxemburger C, Chongsuphajaisiddhi T, White NJ, Nosten F, 2000. Randomized comparison of mefloquine-artesunate ver- 
sus quinine in the treatment of multidrug-resistant falciparum malaria in pregnancy. Trans $R$ Soc Trop Med Hyg 94: 689-693.

36. Looareesuwan S, White NJ, Silamut K, Phillips RE, Warrell DA, 1987. Quinine and severe falciparum malaria in late pregnancy. Acta Leiden 55: 115-120.

37. Nosten F, Karbwang J, White NJ, Honeymoon, Na Bangchang K, Bunnag D, Harinasuta T, 1990. Mefloquine antimalarial prophylaxis in pregnancy: dose finding and pharmacokinetic study. Br J Clin Pharmacol 30: 79-85.

38. McGready R, Stepniewska K, Edstein MD, Cho T, Gilveray G, Looareesuwan S, White NJ, Nosten F, 2003. The pharmacokinetics of atovaquone and proguanil in pregnant women with acute falciparum malaria. Eur J Clin Pharmacol 59: 545552.

39. McGready R, Stepniewska K, Seaton E, Cho T, Cho D, Ginsberg A, Edstein MD, Ashley E, Looareesuwan S, White NJ, Nosten F, 2003. Pregnancy and use of oral contraceptives reduces the biotransformation of proguanil to cycloguanil. Eur J Clin Pharmacol 59: 553-557.

40. Procop GW, Jessen R, Hyde SR, Scheck DN, 2001. Persistence of Plasmodium falciparum in the placenta after apparently effective quinidine/clindamycin therapy. J Perinatol 21: 128-130.

41. Moormann AM, Sullivan AD, Rochford RA, Chensue SW, Bock PJ, Nyirenda T, Meshnick SR, 1999. Malaria and pregnancy: placental cytokine expression and its relationship to intrauterine growth retardation. J Infect Dis 180: 1987-1993.
42. Fried M, Duffy PE, 1996. Adherence of Plasmodium falciparum to chondroitin sulfate A in the human placenta. Science 272: 1502-1504.

43. Fried M, Duffy PE, 1998. Maternal malaria and parasite adhesion. J Mol Med 76: 162-171.

44. Parise ME, Ayisi JG, Nahlen BL, Schultz LJ, Roberts JM, Misore A, Muga R, Oloo AJ, Steketee RW, 1998. Efficacy of sulfadoxine-pyrimethamine for prevention of placental malaria in an area of Kenya with a high prevalence of malaria and human immunodeficiency virus infection. Am J Trop Med Hyg 59: 813-822.

45. Shulman CE, Dorman EK, Talisuna AO, Lowe BS, Nevill C, Snow RW, Jilo H, Peshu N, Bulmer JN, Graham S, Marsh K, 1998. A community randomized controlled trial of insecticidetreated bednets for the prevention of malaria and anaemia among primigravid women on the Kenyan coast. Trop Med Int Health 3: 197-204.

46. Rogerson SJ, Chaluluka E, Kanjala M, Mkundika P, Mhango C, Molyneux ME, 2000. Intermittent sulfadoxine-pyrimethamine in pregnancy: effectiveness against malaria morbidity in Blantyre, Malawi, in 1997-99. Trans R Soc Trop Med Hyg 94: 549553.

47. Cot M, Brutus L, Pinell V, Ramaroson H, Raveloson A, Rabeson D, Rakotonjanabelo AL, 2002. Malaria prevention during pregnancy in unstable transmission areas: the highlands of Madagascar. Trop Med Int Health 7: 565-572. 